Supporting information for

\title{
Comparison of cross-regulation by different OTUB1-E2 complexes
}

\author{
Lauren T. Que ${ }^{1}$, Marie E. Morrow ${ }^{1}$, and Cynthia Wolberger ${ }^{1 *}$
}

${ }^{1}$ Department of Biophysics and Biophysical Chemistry, Johns Hopkins University

School of Medicine, 725 North Wolfe Street, Baltimore, MD 21210-2185 USA

*Email: cwolberg@jhmi.edu

SUPPLEMENTAL INFORMATION

(11 pages including cover sheet)

Tables S1 - S4

Figures S1 - S6 


\begin{tabular}{|c|c|c|c|c|}
\hline Antibody & $\begin{array}{l}\text { Catalogue } \\
\text { Number }\end{array}$ & Supplier & Species & $\begin{array}{l}\text { Dilution in } 2 \% \text { BSA, } 0.02 \% \\
\text { Sodium Azide \& PBS buffer }\end{array}$ \\
\hline UBE2E1 & A-630 & $\begin{array}{c}\text { Boston } \\
\text { Biochem }\end{array}$ & Rabbit & $1: 800$ \\
\hline UBE2E2 & $\mathrm{Ab}-177485$ & Abcam & Rabbit & $1: 5000$ \\
\hline UBE2E3 & PA-551889 & $\begin{array}{l}\text { Thermo } \\
\text { Fisher } \\
\text { Scientific }\end{array}$ & Rabbit & $1: 100$ \\
\hline UBE2N & $4 \mathrm{E} 11$ & Invitrogen & Mouse & $1: 1000$ \\
\hline UBE2D & A-615 & $\begin{array}{c}\text { Boston } \\
\text { Biochem }\end{array}$ & Rabbit & $1: 400$ \\
\hline K48 Ub & $4289 S$ & $\begin{array}{c}\text { Cell } \\
\text { Signaling } \\
\text { Technology }\end{array}$ & Rabbit & $1: 1000$ \\
\hline Ub wt & sc- 8017 & Santa Cruz & Mouse & 1:1000 \\
\hline
\end{tabular}

Table S1. Primary Antibodies. 


\begin{tabular}{|c|c|c|c|c|c|}
\hline Antibody & $\begin{array}{c}\text { Catalogue } \\
\text { Number }\end{array}$ & Supplier & Species & $\begin{array}{c}\text { Anti- } \\
\text { Species }\end{array}$ & $\begin{array}{c}\text { Dilution in } \\
5 \% \\
\text { blocking } \\
\text { buffer \& } \\
\text { TBST }\end{array}$ \\
\hline $\begin{array}{c}\text { HRP-Conjugate IgG } \\
\begin{array}{c}\text { Alex Fluor 594 } \\
\text { conjugate }\end{array}\end{array}$ & A-21203 & ThermoScientific & Donkey & Mouse & $1: 5000$ \\
\hline
\end{tabular}

Table S2. Secondary Antibodies 


\begin{tabular}{|c|c|c|c|c|}
\hline $\begin{array}{c}\text { Proteins } \\
\text { Interacting with } \\
\text { OTUB1 }\end{array}$ & $\mathbf{K}_{\mathbf{d}}(\boldsymbol{\mu} \mathbf{M})$ & $\begin{array}{c}\text { Stoichiometry } \\
\mathbf{( N )}\end{array}$ & $\boldsymbol{\Delta} \mathbf{H}(\mathbf{k c a l} / \mathbf{m o l})$ & $\Delta \mathbf{S}(\mathbf{c a l} / \mathbf{m o l})$ \\
\hline UBE2D1 & $9.3 \pm 1.7$ & $0.8 \pm 0.01$ & $-3 \pm 0.04$ & 12.7 \\
\hline UBE2D2 & $3.9 \pm 1.3$ & $0.9 \pm 0.01$ & $-5 \pm 0.12$ & 8.5 \\
\hline UBE2D3 & $8.1 \pm 3.6$ & $1.2 \pm 0.03$ & $-3.8 \pm 0.11$ & 11.5 \\
\hline UBE2N & $8.1 \pm 2.1$ & $0.7 \pm 0.02$ & $-5.2 \pm 0.16$ & 6 \\
\hline UBE2E1 & $7.3 \pm 1.4$ & $0.9 \pm 0.01$ & $-1.3 \pm 0.03$ & 19.3 \\
\hline
\end{tabular}

Table S3. ITC parameters measured by titrating in OTUB1 into E2 binding partners or K48 diUbiquitin. Experimental data shown in Figure 2. 


\begin{tabular}{|c|c|c|c|c|c|}
\hline Proteins in Cell & $\begin{array}{c}\text { Proteins in } \\
\text { Syringe }\end{array}$ & $\mathbf{K}_{\mathrm{d}}(\boldsymbol{\mu} \mathbf{M})$ & $\begin{array}{c}\text { Stoichiometry } \\
\mathbf{( N )}\end{array}$ & $\begin{array}{c}\Delta \mathbf{H} \\
(\mathbf{k c a l} / \mathbf{m o l})\end{array}$ & $\begin{array}{c}\Delta \mathbf{S} \\
(\mathbf{c a l} / \mathbf{m o l})\end{array}$ \\
\hline OTUB1 (C91S) & K48 diUb & $84.0 \pm 5.0$ & $0.8 \pm 0.02$ & $-12.8 \pm 0.4$ & -24.1 \\
\hline $\begin{array}{c}\text { OTUB1 (C91S) } \\
\text { and UBE2D1 }\end{array}$ & $\begin{array}{c}\text { K48 diUb } \\
\text { and } \\
\text { UBE2D1 }\end{array}$ & $12 \pm 3.9$ & $1.4 \pm 0.02$ & $-10.3 \pm 0.4$ & -12 \\
\hline $\begin{array}{c}\text { OTUB1 (C91S) } \\
\text { and UBE2D3 }\end{array}$ & $\begin{array}{c}\text { K48 diUb } \\
\text { and } \\
\text { UBE2D3 }\end{array}$ & $13.2 \pm 3.6$ & $1.1 \pm 0.03$ & $-75.3 \pm 0.5$ & -22.2 \\
\hline $\begin{array}{c}\text { OTUB1 (C91S) } \\
\text { and UBE2N }\end{array}$ & $\begin{array}{c}\text { K48 diUb } \\
\text { and } \\
\text { UBE2N }\end{array}$ & $22.3 \pm 3.5$ & $2.4 \pm 0.03$ & $-2.2 \pm 0.04$ & 13.9 \\
\hline
\end{tabular}

Table S4. ITC parameters measured by titrating in OTUB1 into E2 binding partners or K48 diUbiquitin. Experimental data shown in Figure 2. 
Figure S1
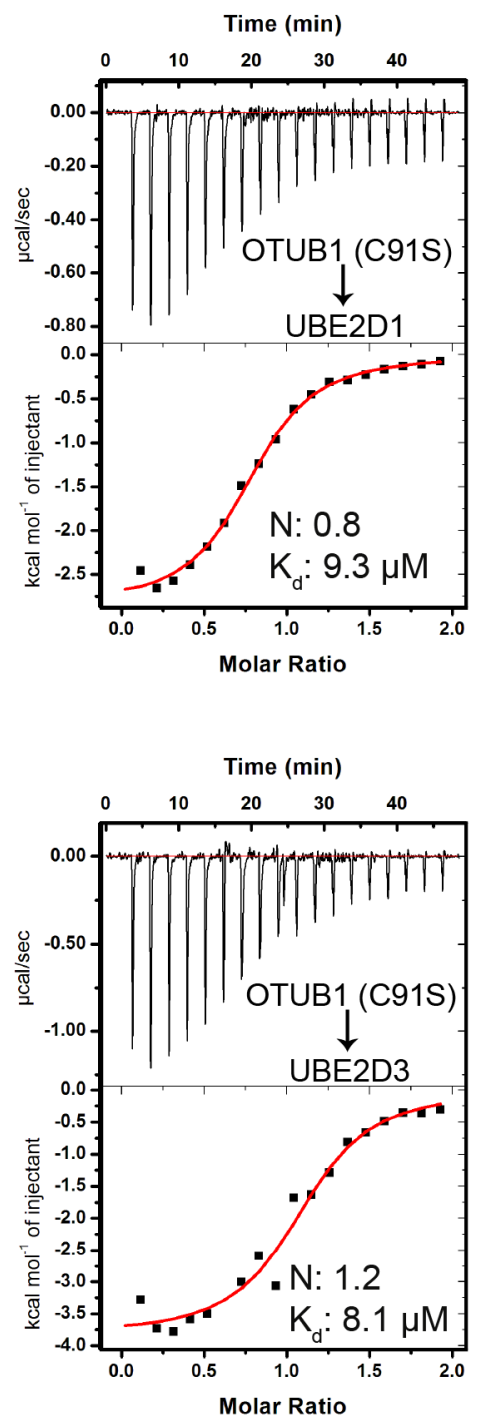

Figure S1. OTUB1 catalytic mutant binds E2s with the same affinity as wild type OTUB1. ITC measurement of the affinity of OTUB1-C91S for UBE2D1 (top) and UBE2D3 (bottom). 
Figure S2

A

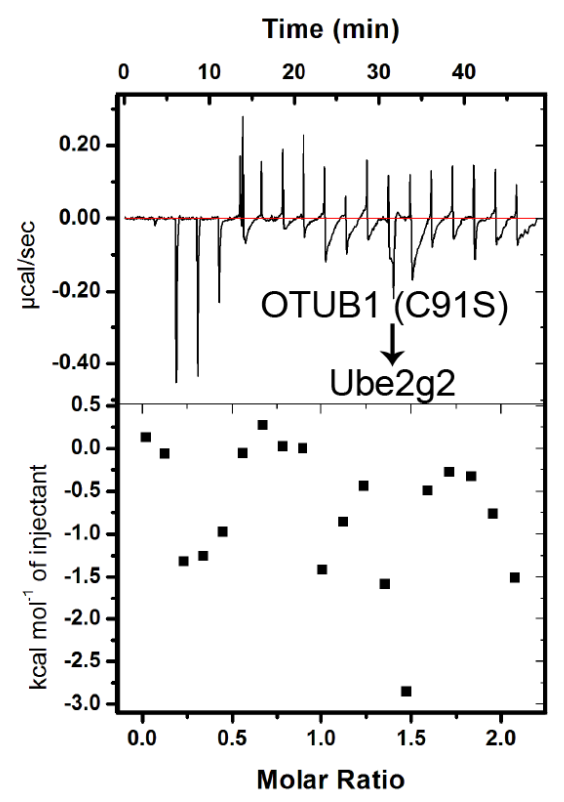

B

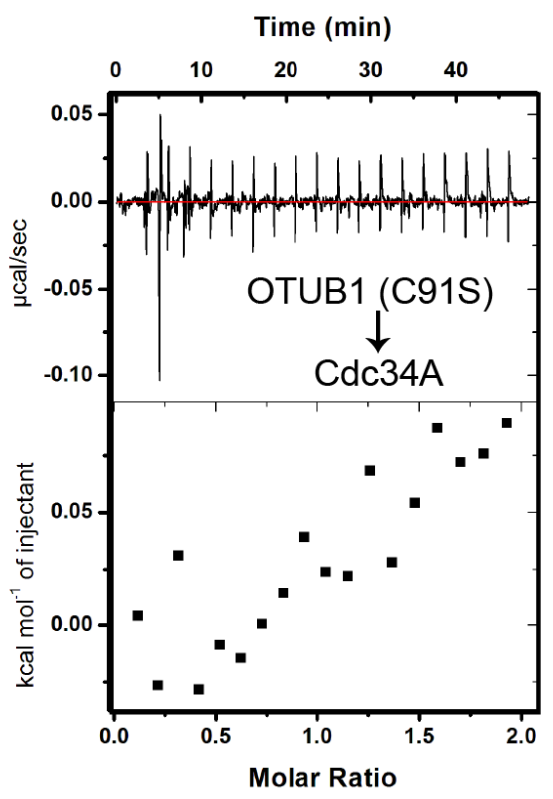

Figure S2. OTUB1 does not bind to CDC34A or UBE2G2. ITC measurements in which OTUB1 $(1.5 \mathrm{mM})$ is titrated into a cell containing $150 \mu \mathrm{M}$ of either Cdc34A or Ube2g2. 
Figure S3

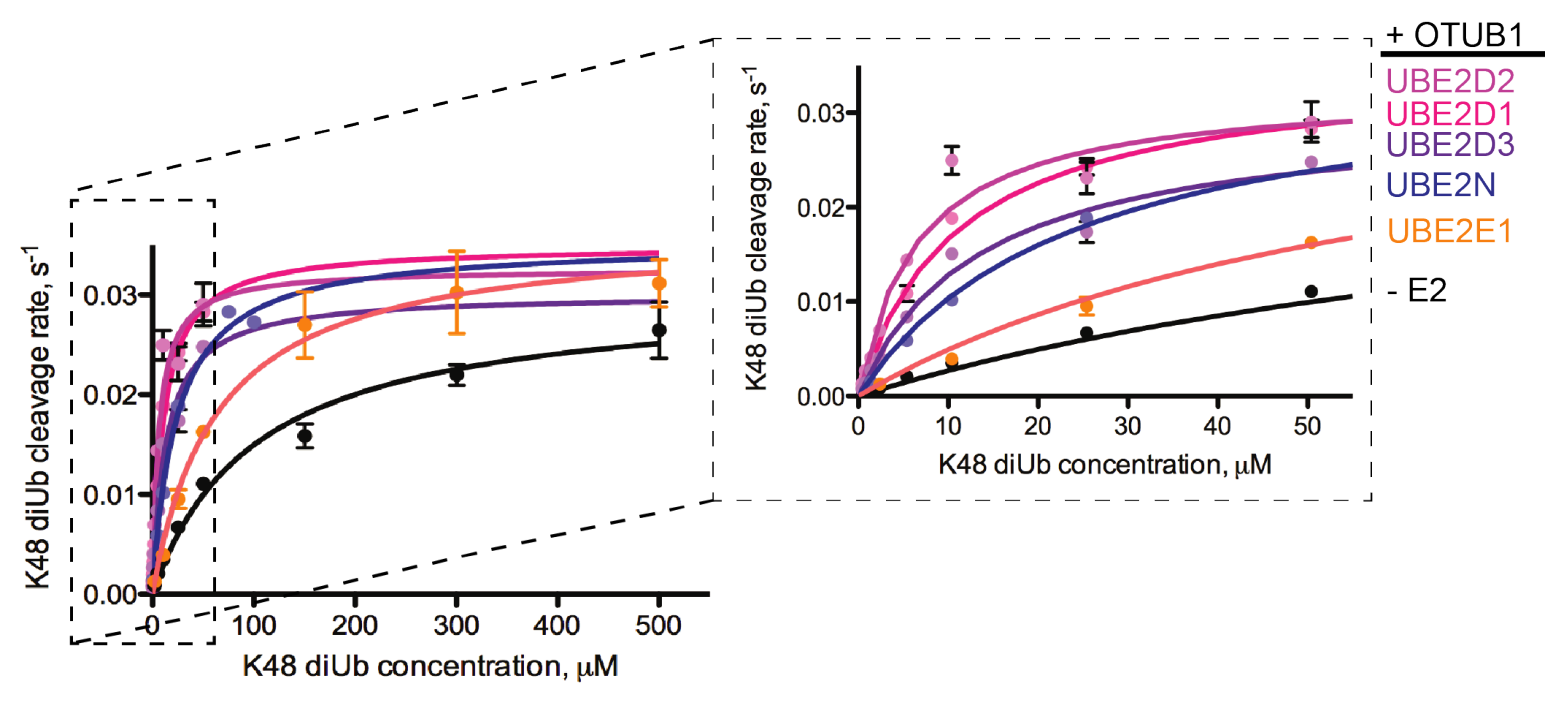

Figure S3. Full kinetic titration showing effect of E2 enzymes on OTUB1 DUB activity Full range titration of K48 diUb $(0.4-500 \mu \mathrm{M})$ to track cleavage by OTUB1 (50 $\mathrm{nM}$ ) in the absence and presence of UBE2D1, UBE2D2, UBE2D3, UBE2N, and UBE2E1 $(10 \mu \mathrm{M})$. Inset indicates region of plot that is shown in Figure 4a. 
Figure S4

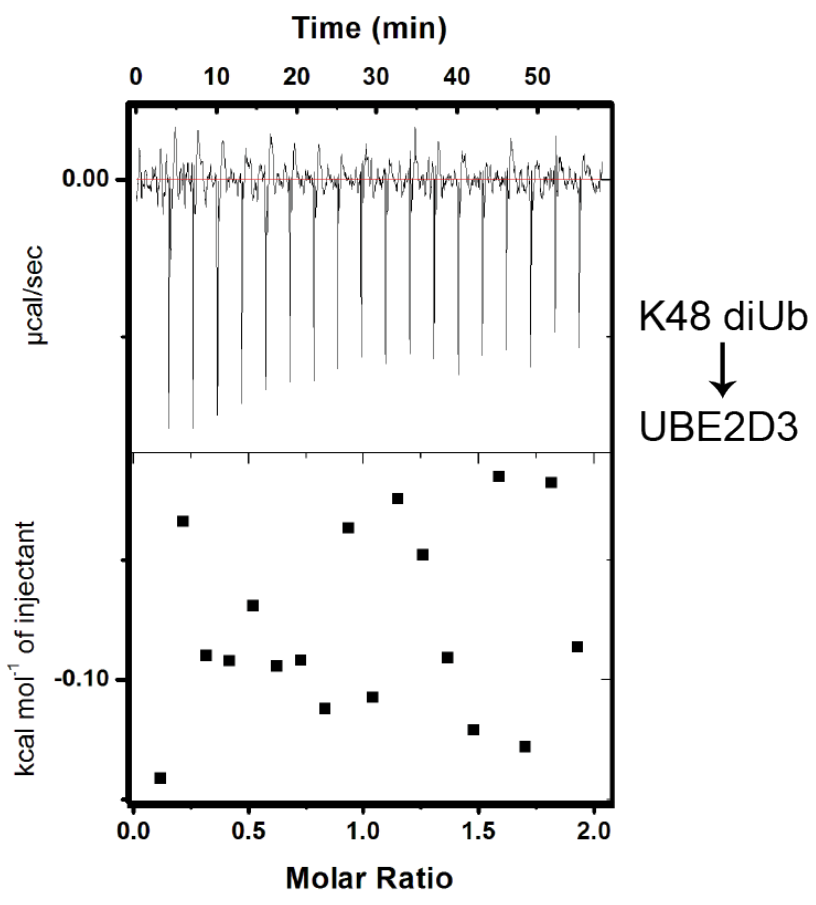

Figure S4. UBE2E3 does not interact detectably with K48 dibuquitin. ITC measurements of Binding of UBE2D3 to K48 diubiquitin. 

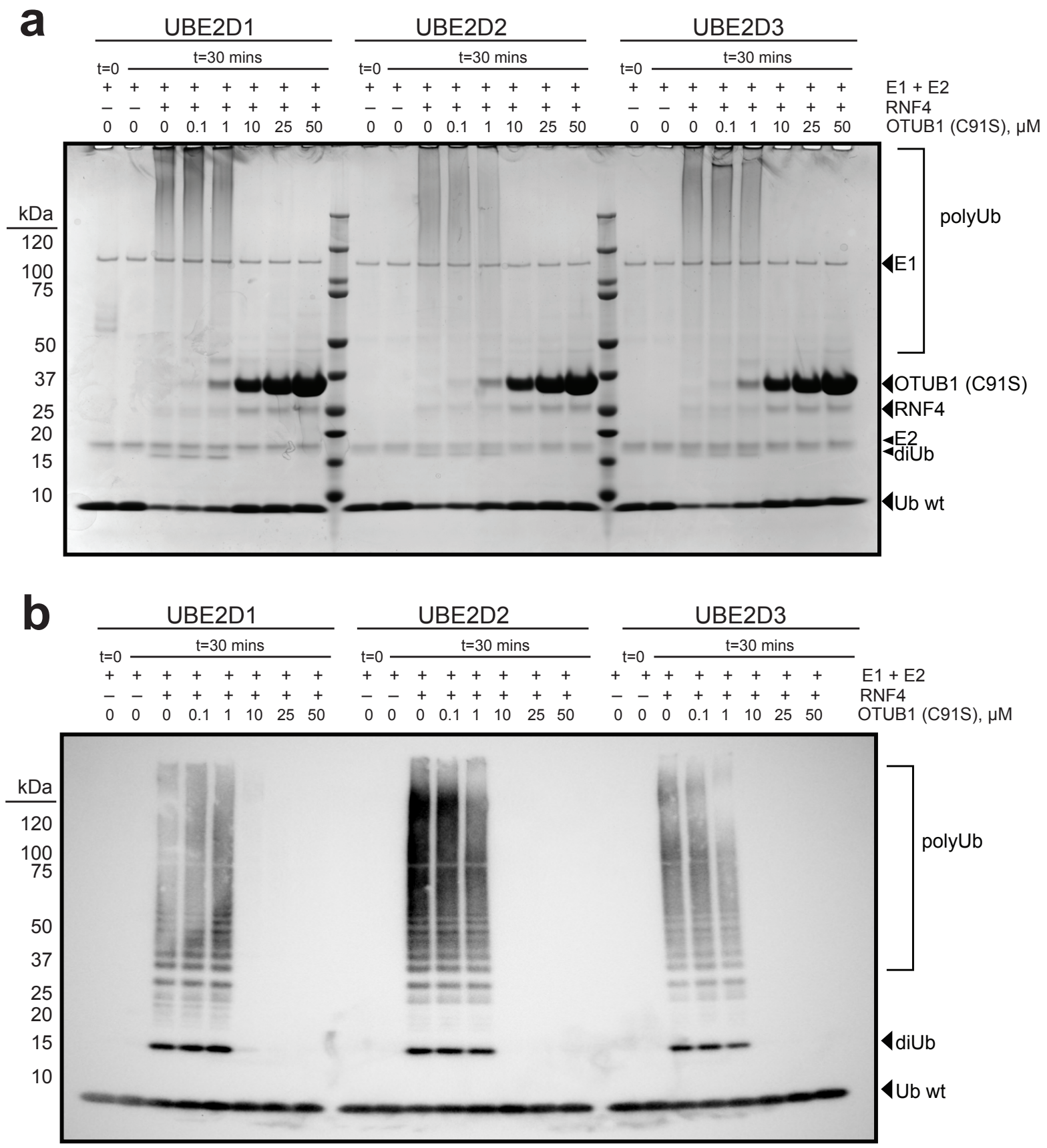

Figure S5. OTUB1 facilitated inhibition of UBE2D. End point reactions quenched at $\mathrm{t}=0$ and 30 mins with increasing concentrations of OTUB1 (C91S) (0-50 $\mu \mathrm{M})$. Each reaction contained $150 \mathrm{nM}$ E1, $2 \mu \mathrm{M}$ E2, $50 \mu \mathrm{M}$ Ub wt, and where applicable, $2 \mu \mathrm{M}$ E3. (a) SDS-PAGE gel stained with Coomassie showing UBE2D(1-3) inhibition by OTUB1 (b) UBE2D inhibition by OTUB1 transferred to membrane and blotted against Ub wt 


\section{Figure S6}

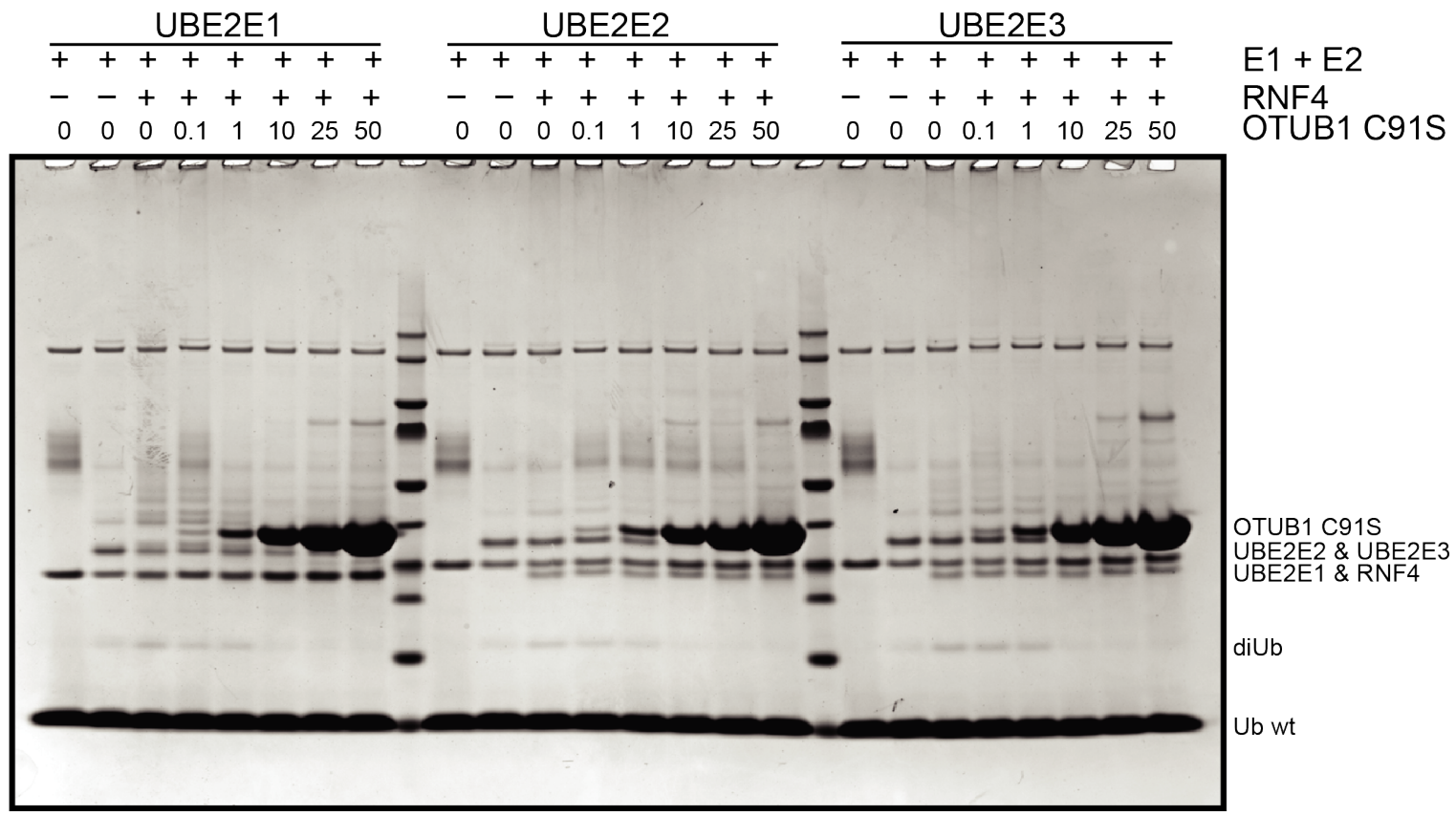

Figure S6. Coomassie stained gel of OTUB1 facilitated inhibition of UBE2E proteins. End point reactions quenched at $\mathrm{t}=0$ and 30 mins with increasing concentrations of OTUB1 (C91S) $(0-50 \mu \mathrm{M})$. Each reaction contained $150 \mathrm{nM} \mathrm{E1}, 2 \mu \mathrm{M}$ E2, $50 \mu \mathrm{M}$ Ub, and where applicable, 2 $\mu \mathrm{M}$ E3. 